\title{
SAMS - participatory development of smart apicultural management services in Ethiopia and Indonesia
}

\author{
Kristina Gratzer ${ }^{a, 1^{\star}}$, Amanda M. Paramita ${ }^{b}$, Katrin Proschek $^{c}$, Magdalena Sperl ${ }^{d}$, \\ Yosef Alemayehu ${ }^{e}$, Sascha Fiedler ${ }^{f}$, Robert Brodschneider ${ }^{a}$ \\ aInstitute of Biology, University of Graz, \\ Universitätsplatz 2, Graz, Austria \\ bLabtek Indie, \\ Jl. Titiran no. 7, Bandung, Indonesia \\ c Technische Hochschule Nürnberg Georg-Simon-Ohm, \\ Keßlerplatz 12, Nuremberg, Germany \\ dDeutsche Gesellschaft für Internationale Zusammenarbeit (GIZ) GmbH, \\ Wielinger Straße 52, Feldafing, Germany \\ eiceaddis IT consultancy, \\ PLCBole Medhanialem, Addis Ababa, Ethiopia \\ fDepartment of Agricultural and Biosystems Engineering, University of Kassel, \\ Nordbahnhofstraße 1a, Witzenhausen, Germany \\ E-mail: kristina.gratzer@uni-graz.at
}

\begin{abstract}
Honey bees can provide income for people in marginalized countries. Beekeeping creates jobs, has low starting costs, does not require to own land and positively contributes to pollination of nearby areas, including farmland. Nevertheless, honey production is reported inefficient or below the production potential in many developing countries. The EU Horizon 2020 project SAMS aimed to improve the bee sectors of the target countries Ethiopia and Indonesia by involving the public in a) creating a SAMS hive monitoring system, b) contextualizing local systems, c) providing beekeeping training and d) business models. A User-Centered Design (UCD) approach guaranteed that the final SAMS products and solutions addressed the needs and requirements of beekeepers in the target countries. Within this article, three important public participation-related outcomes of the SAMS project are described: 1. How we applied UCD in the SAMS project, 2. co-creation of personas to classify beekeeper characteristics in Ethiopia and Indonesia and 3. local design and constructions of homes for bees. All (co-)created outcomes, like manuals, are freely available.
\end{abstract}




\section{Introduction}

Beekeeping and honey production do not necessarily require land ownership, making it especially attractive for generating income and improving livelihoods of the rural poor [1], [2]. Next to bee products, the polylectic honey bee provides important pollination services. The economic value of pollinators, in general, was recently estimated to equal about one percent of the global GDP [3]. To facilitate beekeeping as a source of income, the European Union funded project SAMS (Smart Apiculture Management Services) aimed to improve beekeeping in Ethiopia and Indonesia via various ways. These included, amongst others, the development of a hive monitoring system, assessment of the national bee sectors, development of business models, beekeeping and beehive construction training [4]. As not every beekeeping program in developing countries has been reported to be successful [5], we decided to focus on public participation in many project areas by a User-Centered Design (UCD) approach. The UCD process involved workshops with beekeepers, students and other citizens to create visions for the development of beekeeping. The project involved also grassroot activities, like hive construction co-creation workshops. To guarantee a best practice and customized SAMS hive monitoring system and a successful developing program, all creation processes had the user in the center of all iterations.

\section{User-Centered Design in the SAMS project}

The SAMS UCD approach is based on a procedure model describing the interdependence of human-centered design activities defined in DIN ISO 9241-210. This framework was used to ensure that needs, demands, and limitations of users are in the focus within the project and all steps of the project development. Iterations of analyzing the context, specifying the user requirements, producing solutions, and evaluating them are recommended when following the UCD approach - as well as agile development and meeting regularly. However, theory and practical approaches often differ from each other. So does applying UCD under real co-creation conditions and among a multi-disciplinary and multi-cultural team in the multi-product SAMS project. A UCD roadmap, which was adjusted throughout the project running time, was guiding the project team. Following the UCD co-creation approach, all hardware, software and apicultural project solutions are characterized by iterations of product design and user evaluation as well as iterations to the context of user analysis and user requirements specifications in order to refine the product (Figure 1). They range from definitions and user research to honey bee management suggestions, the SAMSwiki, a UCD glossary, business models, SAMS partnerships and technical results like the SAMS hive monitoring system, the user interface of the Decision Support System (DSS), SAMS data display for beekeepers and the Data Warehouse (DW).

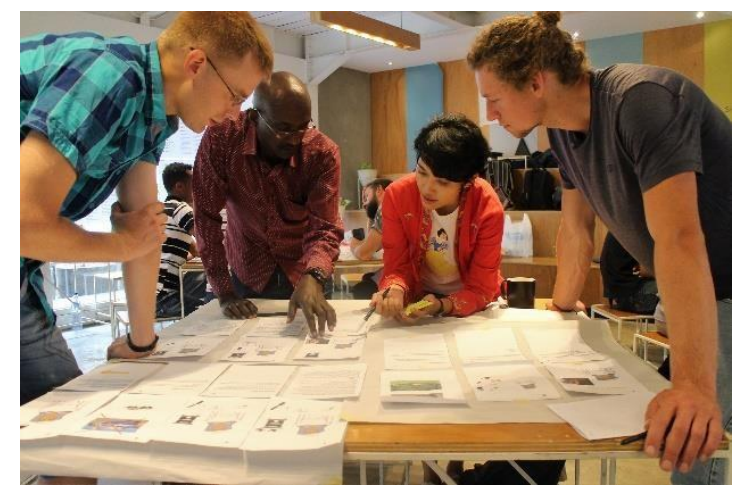

Figure 1: UCD workshop in Bandung (Indonesia). 


\section{Identify local beekeeper characteristics}

Identifying the most important types of beekeepers in Ethiopia and Indonesia and comprising them into "personas" was one of the results of the UCD process (Figure 2). Personas reflect users based on empirically determined data (interviews or observations) by age, background information, interests and beekeeping knowledge. They collectively represent the majority of beekeepers in Ethiopia and Indonesia. The Ethiopian persona Tadese represents traditional countryside beekeepers. Abrash represents the extension workers as well as small-scale modern beekeepers living in small towns and suburbs of the cities. Degen is characterizing modern beekeepers and is interested in large-scale beekeeping and high financial incentive. For Indonesia, initially four personas were created and during the research process, they were further refined. Here, we present two of them: Usep and Sopian are both middle-aged men and smartphone users. Social media acts as support for their beekeeping businesses. While Usep lives in a rural area and is a full-time beekeeper, Sopian lives in a peri urban region and conducts beekeeping as a side activity.

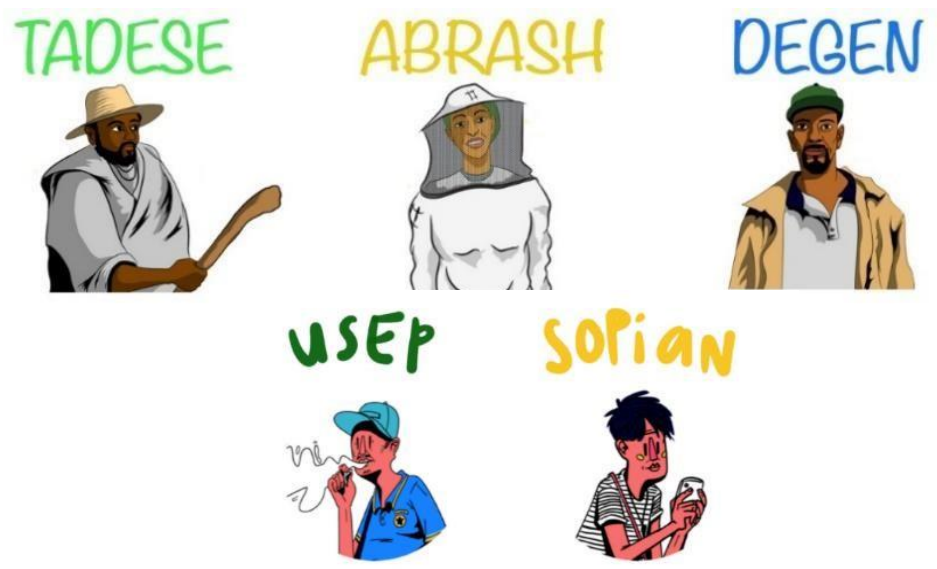

Figure 2: Illustrations of three Ethiopian (above) and two Indonesian (below) personas (beekeeper personalities) created with the SAMS UCD approach helps to tailor solutions based on user needs.

The constructed personas were used to describe as-is scenarios for key beekeeping practices. Personas and scenarios helped to understand user needs and identified system-related user requirements for SAMS products such as the monitoring system itself and the DSS system for beekeepers on smartphones.

\section{Building homes for bees}

In Ethiopia, approximately $95 \%$ of hive types are made from easily accessible traditional materials (Figure 3ab) [6]. Beekeepers using them have no investment costs but are unable to conduct internal hive inspections or manipulations. Management possibilities and honey productivity are considered to be higher in transitional (Figure 3c) or modern hive systems (Figure 3d). To foster the use of such systems, a construction manual for a modern hive similar to the globally popular Langstroth type was developed within the SAMS project. Interested citizens were invited to co-creation workshops for further improvement of the hive design and for learning to construct the hive for their own use. 

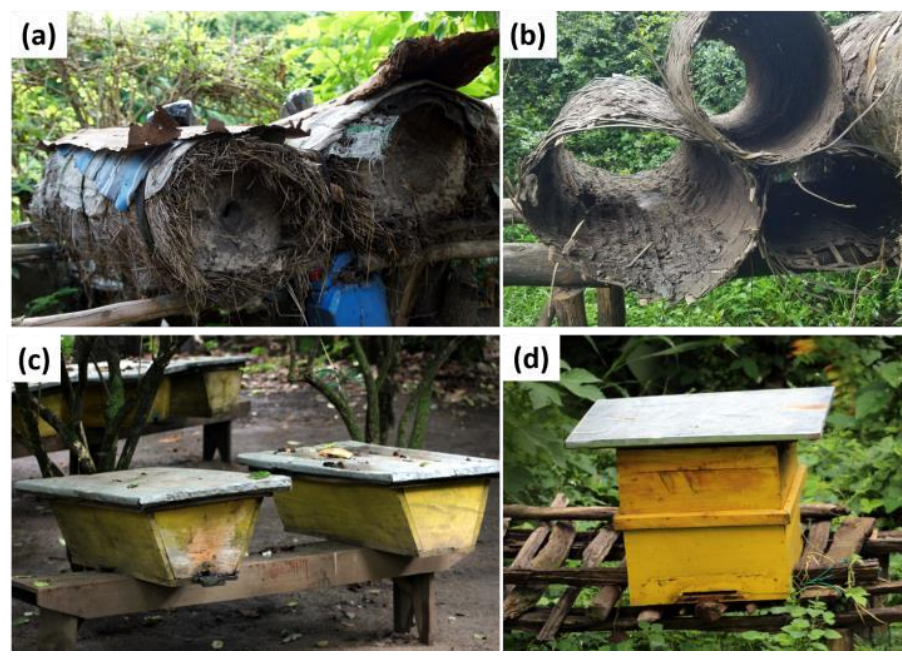

Figure 3: Common hive types in Ethiopia. (a) and (b) traditional, (c) transitional and (d) modern hive systems.

In Indonesia, several species of bees are kept [7]. While in Ethiopia, modern hives have common size types (e.g., Langstroth, Dadant or Zander), in Indonesia no such standardized beehive dimensions exist. Beekeepers managing the introduced A. mellifera use larger hives (Figure 4a). For A. cerana either upcycled wood, or clean-cut wood is used to construct smaller hives (Figure 4cd). Besides honey bees, stingless bees are kept in small and simple boxes (Figure 4b). Similar to Ethiopia, grassroot activities were organized in Indonesia, although the aim was a different one - namely to push forward the use of standardized beehive dimensions (Figure 5).

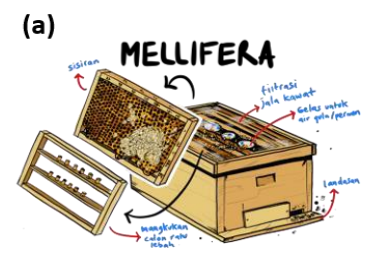

(c) (b)

\section{TRIGONA}

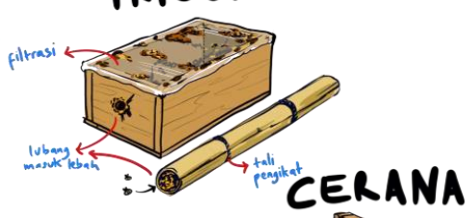

(d)

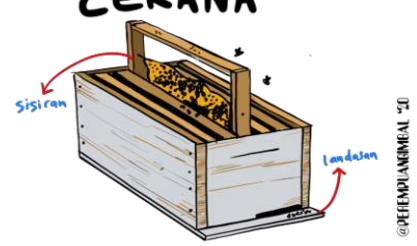

Figure 4: Indonesian variations in beehive types were identified and illustrated: (a) typically used hive for A. mellifera, (b) Trigona spp., (c) A. cerana (built by using upcycled wood) and (d) A. cerana hive from clear-cut wood.
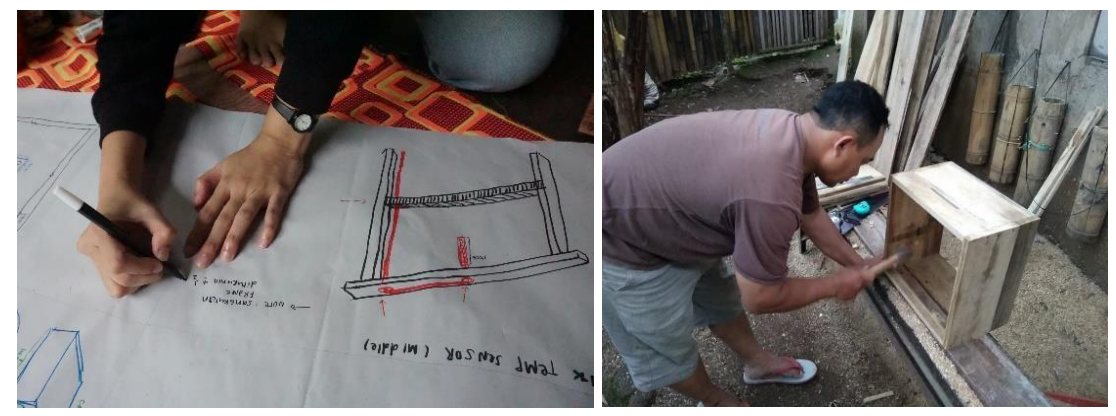

Figure 5: SAMS beehive construction activity in Indonesia. 


\section{Conclusion}

The reward of including UCD methods and grassroot activities in the SAMS co-creation process provided deeper insight into a variety of contextual factors resulting in customized solutions for sustainable beekeeping. Another important aspect was to make all project outputs available to the public by providing access to an online database (wiki.sams-project.eu), allowing the utilization and further adaptation of project outcomes. Propagation of beekeeping in marginalized countries and custom-made beekeeping monitoring systems have the potential to foster employment and open up new possibilities for people along the honey value chain. To accelerate the comprehensive access to technological aid, more participatory research needs to be conducted especially in countries, where basic knowledge on bees and beekeeping has not been well communicated so far.

\section{References}

[1] R.K. Gupta, W. Reybroeck, J.W. van Veen, A. Gupta, Beekeeping for Poverty Alleviation and Livelihood Security: Vol. 1: Technological Aspects of Beekeeping. Dordrecht, Springer Netherlands (2014).

[2] C.N. Schouten, D. Lloyd, R.W. Sengere, J. Aranka, Optimising beekeeping development programs for improved productivity, income and welfare: A case study of Papua New Guinea. JARTS 121 (2020), 195-206. DOI: 10.17170/kobra-202007291511

[3] C. Lippert, A. Feuerbacher, M. Narjes, Revisiting the economic valuation of agricultural losses due to large-scale changes in pollinator populations, Ecological Economics 180 (2021), 106860. DOI: 10.1016/j.ecolecon.2020.106860

[4] Kibebew Wakjira, Taye Negera, Aleksejs Zacepins, ..., Robert Brodschneider Smart Apiculture Management Services for developing countries the case of SAMS project in Ethiopia and Indonesia. PeerJ Computer Science (in press).

[5] C.N. Schouten, D.J. Lloyd, Considerations and Factors Influencing the Success of Beekeeping Programs in Developing Countries. Bee World 96 (2019), 75-80. DOI:

10.1080/0005772X.2019.1607805

[6] T.K. Degu, G.R. Megerssa, Role of Beekeeping in the Community Forest Conservation: Evidence from Ethiopia, Bee World, 97 (2020), 98-104. DOI: 10.1080/0005772X.2020.1825308

[7] K. Gratzer, F. Susilo, D. Purnomo, S. Fiedler, R. Brodschneider, Challenges for Beekeeping in Indonesia with Autochthonous and Introduced Bees, Bee World, 96 (2019), 40-44. DOI:

10.1080/0005772X.2019.1571211

\section{Acknowledgements}

We thank the beekeepers for their contribution. The research has received funding from the European Union's Horizon 2020 research and innovation project SAMS - "Smart Apiculture Management Systems" (Grant Agreement N ${ }^{\circ}$ 780755). 